\title{
Conservative management of traumatic acute intramural hematoma of duodenal 2nd and 3rd portion: A case report and review of literature
}

\author{
Sun Jeong Kim ${ }^{1}$, Jin Ho Lee ${ }^{1}$, Su Mi Park ${ }^{2}$, and Kuk Hwan Kwon ${ }^{1}$ \\ ${ }^{1}$ Department of Surgery, National Health Insurance Service Ilsan Hospital, \\ ${ }^{2}$ Department of Radiology, National Health Insurance Service Ilsan Hospital, Goyang, Korea
}

\begin{abstract}
Traumatic intramural duodenal hematoma $(\mathrm{IMDH})$ is a rare disease occurring usually in children. The treatment modality of traumatic IMDH varies according to clinical manifestations. We had a case of a young man who had traumatic $\mathrm{IMDH}$ and treated nonoperatively. He had 3 weeks of conservative care and has been discharged, with follow up abdominal CT scan showing complete resolution of the hematoma. In conclusion, patient with traumatic acute intramural hematoma of duodenal 2nd and 3rd portion have excellent clinical outcomes with conservative therapy. (Ann Hepatobiliary Pancreat Surg 2020;24:109-113)
\end{abstract}

Key Words: Hematoma; Duodenum; Trauma; Conservative management

\section{INTRODUCTION}

Traumatic intramural duodenal hematoma (IMDH) is a rare disease occurring usually in childhood. However, cases of IMDH has steadily been reported in many institutions worldwide. The treatment modality varies according to the symptoms, clinical manifestations and complications presented by patients. Here we introduce a case of a young man with a IMDH caused by traumatic event, who has been treated nonoperatively for 3 weeks and has been discharged with no specific complications.

\section{CASE}

A 17-year-old male patient who had been vomiting and had poor oral intake for 4 days was admitted to our institution, after visiting another hospital. There he underwent an upper gastric endoscopy for further evaluation of any cause of gastric outlet obstruction symptoms. Upper endoscopy revealed the erosion with hyperemic mucosa in the duodenal bulb and complete obstruction of the second duodenal portion caused by external compression. Following abdominal $\mathrm{CT}$ scan revealed a large mass (about $8.7 \times 4.5 \times 5 \mathrm{~cm}$ ) with an internal hemorrhage abutting and compressing the lumen of the duodenal second and third portion (Fig. 1A, B). With the diagnosis of enteric cyst of duodenum 2 nd-3rd, he was sent to our hospital for surgical management. And esophagogastroduodenoscopy (EGD) showing extrinsic compression and ulcerative mass like lesion of duodenum 2 nd and 3rd portion (Fig. 1C, D).

On his arrival to our hospital, there was no mention of any traumatic events written on referral from the other hospital, so we neglected the possibility of traumatic causes. We decided to take MRI scan to further distinguish the structural relationship of the cyst from other adjacent organs. The source of the GI symptoms revealed in MRI scan was found to be the acute intramural hematoma of duodenal 2nd and 3rd portion, and localized geographic infiltrative lesion of subcutaneous fat tissue of right anterior abdominal wall (Fig. 1E, F). At the same time, we found out that the patient had the traumatic event

Received: July 11, 2019; Revised: July 24, 2019; Accepted: July 25, 2019

Corresponding author: Jin Ho Lee

Division of Hepato-Bilio-Pancreas Surgery, Department of Surgery, National Health Insurance Service Ilsan Hospital, 100 Ilsan-ro, Ilsandong-gu, Goyang 10444, Korea

Tel: +82-31-900-3491, Fax: +82-31-900-0138, E-mail: jinholee75@nhimc.or.kr

Copyright (C) 2020 by The Korean Association of Hepato-Biliary-Pancreatic Surgery

This is an Open Access article distributed under the terms of the Creative Commons Attribution Non-Commercial License (http://creativecommons.org/ licenses/by-nc/4.0) which permits unrestricted non-commercial use, distribution, and reproduction in any medium, provided the original work is properly cited. Annals of Hepato-Biliary-Pancreatic Surgery • pISSN: 2508-5778 - elSSN: 2508-5859 

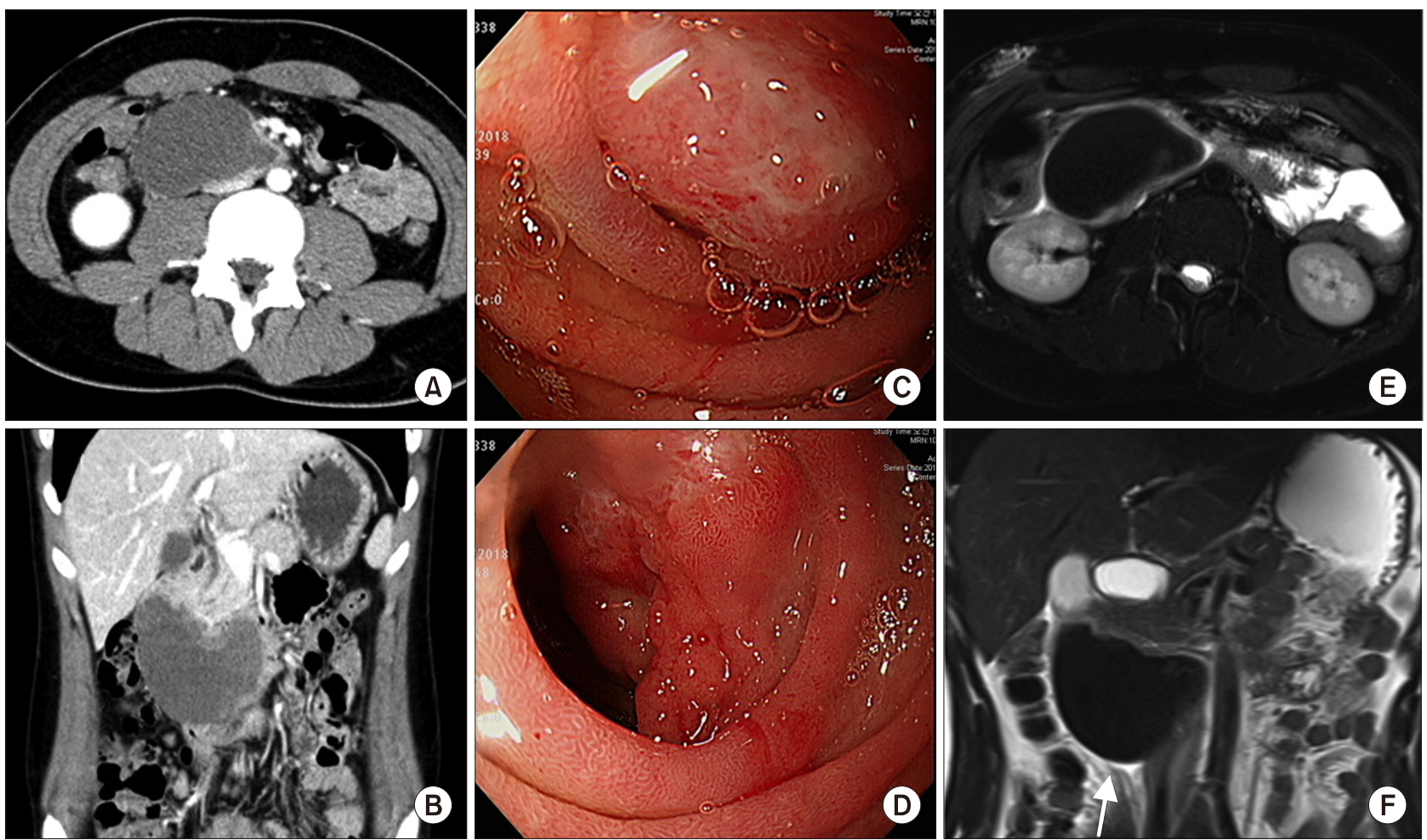

Fig. 1. (A), (B) are axial and coronal view of abdominopelvic CT, showing intramural hematoma of duodenum 2 nd and $3 \mathrm{rd}$ portion. (C), (D) are endoscopic finding, showing extrinsic compression and ulcerative mass like lesion of duodenum 2 nd and 3rd portion. (E), (F) are axial and coronal view of MRI, showing about $8.5 \times 5.5 \times 4.5 \mathrm{~cm}$, acute intramural hematoma of duodenal 2nd and third portion.
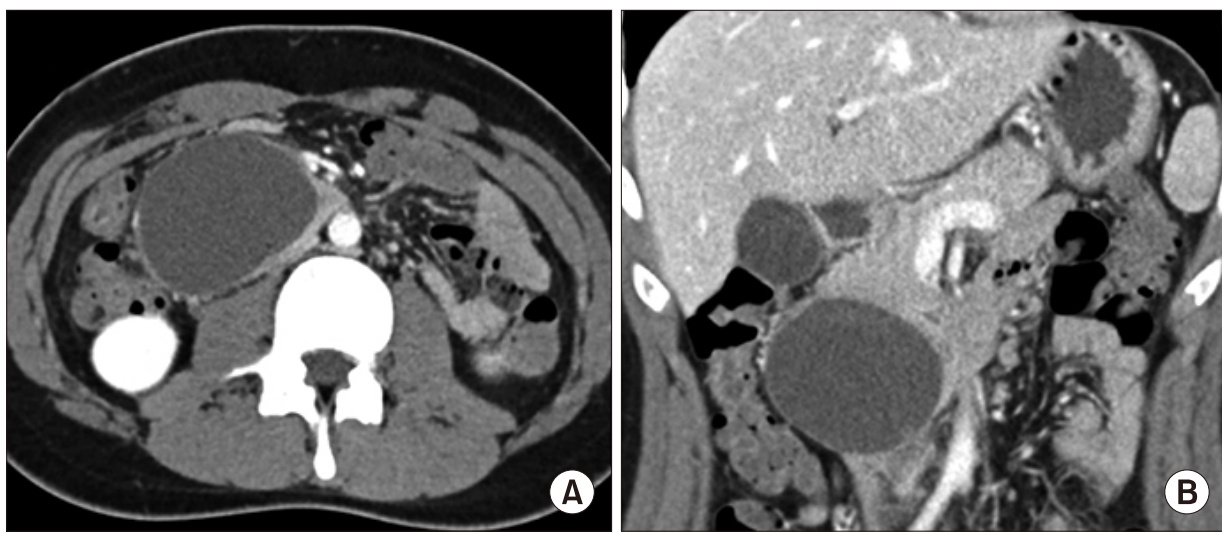

Fig. 2. Abdominopelvic CT follow up taken on 14th day of admission showed minimal decrease in size of intramural hematoma of duodenum. (A) is axial view and (B) is coronal view.
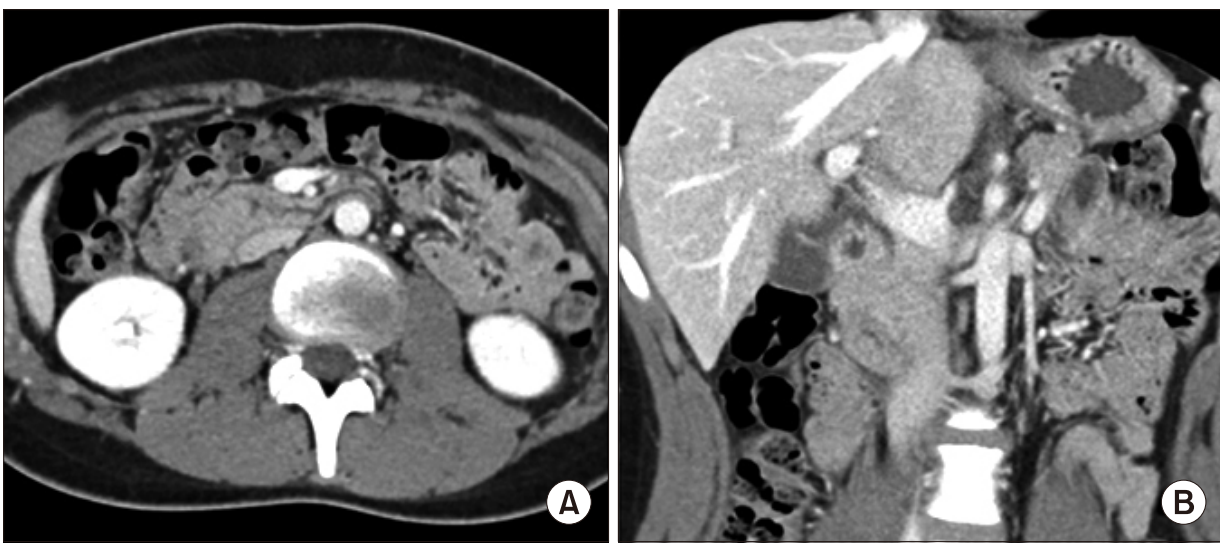

Fig. 3. Abdominopelvic CT follow up taken on 7th week after diagnosis of IMDH showed completely resolved with very minimal periduodenal fluid left. (A) is axial view and (B) is coronal view. 
the day before the symptoms developed, where he tripped on the threshold and hit his upper stomach hard on the metal doorknob which caused him significant pain. Excluding any hereditary coagulopathy or hemorrhage disease history, we diagnosed him with traumatic intramural duodenal hematoma.

Since there is no standard treatment for traumatic intramural duodenal hematoma, and considering the fact that the patient had to take a national evaluation of educational achievement test in few weeks, we decided to take on conservative management rather than an invasive surgical treatment. Total parenteral nutritional therapy with adequate fluid replacement and nil per os (NPO) was applied. Levin tube insertion was not necessary since there was no significant gastro stasis. The patient was administered 2nd generation cephalosporin antibiotics. B1ood tests were taken approximately twice a week to examine abnormalities of hemoglobin decreases or electrolytes imbalance caused with NPO. Soon after, the patient was able to take some sips of water or small bites of fruits with no abdominal discomfort or vomiting.

On the 14th day of admission, which also showed rare decrease in size of IMDH (Fig. 2). And the patient was able to eat small amounts of soft diets tolerably. Nevertheless, the patient was able to eat tolerable amount of food with no IV fluid replacement. After the patient took the national evaluation of educational achievement test, as the patient resolved in symptoms of vomiting and poor oral intake, we decided to further follow up the CT scan after 1 month of discharge.

7 weeks after the diagnosis of IMDH, the patient revisited the outpatient clinic with 3rd follow up CT scan. On the CT scan, the intramural hematoma located in 2nd to 3rd portion of duodenum has completely resolved with very minimal periduodenal fluid left (Fig. 3). The patient had no limitations to consuming foods. We decided not to further follow up the patient.

\section{DISCUSSION}

The traumatic duodenal injuries occur in the $3-5 \%$ of blunt abdominal traumas. ${ }^{1,2}$ The examples of blunt traumatic duodenal injuries include traffic accidents, fall down injuries, assaulting injuries and handlebar injury. The duodenal injury is caused by compression of duodenum against the spine, which results in duodenal hematoma, laceration and perforation. ${ }^{3}$

Intramural hematoma of the duodenum (IMDH) was first described in 1838 by McLauchlan, who described "false aneurysmal tumor occupying nearly the whole of the duodenum" in the autopsy note of the man died of dehydration duodenal obstruction. ${ }^{4}$ The etiologies of IMDH are categorized into external injury, internal injury and spontaneous. IMDH is caused by external injuries and trauma has been largely reported in the pediatric patients. ${ }^{3,5,6}$ Internal injury of IMDH is characterized as

Table 1. Previously reported treatment cases of intramural duodenal hematoma (IMDH)

\begin{tabular}{|c|c|c|c|c|c|c|c|c|}
\hline \multirow{2}{*}{ Author } & \multirow{2}{*}{ Publish } & \multirow{2}{*}{ Case } & \multirow{2}{*}{ Etiology of IMDH } & \multicolumn{5}{|c|}{ Management } \\
\hline & & & & Surgery & Conservative & TAE & Endoscopy & PCD \\
\hline Peterson et $\mathrm{al}^{6}$ & 2015 & 19 & Blunt trauma & 5 & 13 & & & 1 \\
\hline Sahn et $\mathrm{al}^{7}$ & 2015 & 29 & EGD, blunt trauma & & 29 & & & \\
\hline Lourenço et $\mathrm{al}^{8}$ & 2017 & 1 & Alcoholic pancreatitis & & 1 & & & \\
\hline Chang et $\mathrm{al}^{9}$ & 2015 & 1 & Alcoholic pancreatitis & & 1 & & & \\
\hline $\begin{array}{l}\text { Abdel Samie and } \\
\text { Theilmann }{ }^{10}\end{array}$ & 2013 & 4 & Anticoagulatioin & 2 & 2 & & & \\
\hline Eurboonyanun et $\mathrm{al}^{12}$ & 2016 & 1 & Alcoholic pancreatitis & & 1 & & & \\
\hline Margolis et $\mathrm{al}^{13}$ & 1976 & 5 & Blunt trauma & 5 & & & & \\
\hline Elmoghazy et $\mathrm{al}^{14}$ & 2015 & 1 & Pancreatitis & 1 & 1 & & & \\
\hline Takishima et $\mathrm{al}^{15}$ & 2000 & 1 & Blunt trauma & & & & & \\
\hline Lee et $\mathrm{al}^{16}$ & 2012 & 1 & Alcoholic pancreatitis & & & & 1 & \\
\hline Yang et $\mathrm{al}^{17}$ & 2008 & 1 & Blunt trauma & & & & & 1 \\
\hline $\mathrm{D}^{\prime}$ Arpa et $\mathrm{al}^{18}$ & 2015 & 1 & Blunt trauma & & 1 & & & \\
\hline
\end{tabular}

TAE, transaterial embolizatioin; PCD, percutaneous drainage; EGD, esophagogstroduodenoscopy 
endoscopic injury; endoscopy itself or endoscopic biopsy. ${ }^{7}$ Approximately one out of 2000 patients who receives EGD develops duodenal hematoma. pancreatitis is often thought to irritate the bowel to develop hematoma., Some patients develop spontaneous hematoma due to their bleeding risks, such as anticoagulant agent intake. ${ }^{10}$ Some patients have no significant cause for the spontaneous duodenal hematoma. ${ }^{11}$ Duodenal hematoma frequently causes gastric obstruction represented as abdominal pain and vomiting. Furthermore upper gastrointestinal bleeding, jaundice, and acute pancreatitis may also be present. ${ }^{12}$

There are few cases that treated duodenal hematoma with invasive procedures. In the past, surgical treatment such as evacuation of hematoma or bypass surgery was performed. $^{13}$ The lack of radiologic diagnosis had surgeons perform exploratory laparotomy after blunt trauma of the abdomen. Today, surgical procedures are often needed in intra-abdominal complications such as uncontrolled bleeding or panperitonitis. ${ }^{14}$ Delayed bowel obstruction and jaundice often led to laparotomy cases. ${ }^{15}$ Endoscopic drainage with mucosal puncture or fistula formation has also been performed without significant complications. ${ }^{16}$ If accessible through the skin, percutaneous catheter insertion was also performed for decompression of IMDH. $^{17}$

However, several case reviews and retrospective studies revealed the effectiveness of conservative care in traumatic IMDH. ${ }^{6-9,18}$ The median resolution of the IMDH is 7.69 days and the length of stay in hospital was longer in grade II duodenal injury of AAST duodenal injury scale (involving more than one portion) than in grade I duodenal injury (involving single portion). No apparent limitation of nonoperative treatments was noted, with little complications. Moreover, not only in traumatic but also IMDH caused by other etiologies are now treated with less invasive methods. ${ }^{7}$ Table 1 summarizes the previously reported treatment cases of intramural duodenal hematoma. Of the 65 patient, conservative treatment was performed in 49 patient. And thirteen patients underwent surgical treatment, percutaneous drainage in two patient, and endoscopic drainage in one patient.

Traumatic acute intramural hematoma of duodenum is rare. A thorough history taking and adequate radiologic exams are essential for diagnosis of traumatic intramural hematoma of duodenum. Patient with traumatic acute in- tramural hematoma of duodenal 2nd and 3rd portion have excellent clinical outcomes with conservative therapy.

\section{ORCID}

Sun Jeong Kim: https://orcid.org/0000-0002-4588-7309

Jin Ho Lee: https://orcid.org/0000-0001-5791-4442

Su Mi Park: https://orcid.org/0000-0002-8130-0368

Kuk Hwan Kwon: https://orcid.org/0000-0002-6665-6577

\section{AUTHOR CONTRIBUTIONS}

Conceptualization: JHL. Data curation: SJK, JHL, KHK. Formal analysis: SJK, SMP. Methodology: JHL, SMP, KHK Project administration: JHL, SJK. Visualization: JHL, SJK. Writing - original draft: JHL, SJK. Writing - review \& editing: JHL.

\section{REFERENCES}

1. Ivatury RR, Nassoura ZE, Simon RJ, Rodriguez A. Complex duodenal injuries. Surg Clin North Am 1996;76:797-812.

2. Carrillo EH, Richardson JD, Miller FB. Evolution in the management of duodenal injuries. J Trauma 1996;40:1037-1045; discussion 1045-1046.

3. Gutierrez IM, Mooney DP. Operative blunt duodenal injury in children: a multi-institutional review. J Pediatr Surg 2012;47: 1833-1836.

4. McLauchlan J. Fatal false aneurysmal tumour occupying nearly the whole of the duodenum. Lancet 1838;30:203-205.

5. Clendenon JN, Meyers RL, Nance ML, Scaife ER. Management of duodenal injuries in children. J Pediatr Surg 2004;39:964-968.

6. Peterson ML, Abbas PI, Fallon SC, Naik-Mathuria BJ, Rodriguez JR. Management of traumatic duodenal hematomas in children. J Surg Res 2015;199:126-129.

7. Sahn B, Anupindi SA, Dadhania NJ, Kelsen JR, Nance ML, Mamula P. Duodenal hematoma following EGD: comparison with blunt abdominal trauma-induced duodenal hematoma. J Pediatr Gastroenterol Nutr 2015;60:69-74.

8. Lourenço LC, Horta DV, Reis J. Hepatobiliary and pancreatic: gastric outlet obstruction from pancreatitis-induced intramural duodenal haematoma. J Gastroenterol Hepatol 2017;32:739.

9. Chang CM, Huang HH, How CK. Acute pancreatitis with an intramural duodenal hematoma. Intern Med 2015;54:755-757.

10. Abdel Samie A, Theilmann L. Risk factors and management of anticoagulant-induced intramural hematoma of the gastrointestinal tract. Eur J Trauma Emerg Surg 2013;39:191-194.

11. Hashimoto R, Chonan A. A nontraumatic intramural duodenal hematoma causing gastric outlet obstruction. Turk J Gastroenterol 2016;27:470-471.

12. Eurboonyanun C, Somsap K, Ruangwannasak S, Sripanaskul A. Spontaneous intramural duodenal hematoma: pancreatitis, obstructive jaundice, and upper intestinal obstruction. Case Rep Surg 2016;2016:5321081.

13. Margolis IB, Carnazzo AJ, Finn MP. Intramural hematoma of 
the duodenum. Am J Surg 1976;132:779-783.

14. Elmoghazy W, Noaman I, Mahfouz AE, Elaffandi A, Khalaf H. Surgical management of complicated intra-mural duodenal hematoma: a case-report and review of literature. Int J Surg Case Rep 2015;17:103-105.

15. Takishima T, Hirata M, Kataoka Y, Naito T, Ohwada T, Kakita A. Delayed development of obstructive jaundice and pancreatitis resulting from traumatic intramural hematoma of the duodenum: report of a case requiring deferred laparotomy. J Trauma 2000;49:160-162.
16. Lee JY, Chung JS, Kim TH. Successful endoscopic decompression for intramural duodenal hematoma with gastric outlet obstruction complicating acute pancreatitis. Clin Endosc 2012;45:202-204.

17. Yang JC, Rivard DC, Morello FP, Ostlie DJ. Successful percutaneous drainage of duodenal hematoma after blunt trauma. J Pediatr Surg 2008;43:e13-e15.

18. D'Arpa F, Orlando G, Tutino R, Salamone G, Battaglia EO, Gulotta G. Traumatic isolated intramural duodenal hematoma causing intestinal obstruction. ACG Case Rep J 2015;2:198-199. 